\title{
Therapeutic and evolutionary characteristics of Diabetic ketosis decompensations after a decade at the University Hospital of Cotonou, Benin
}

Gninkoun Comlan Jules ${ }^{*}$, Alassani Adébayo ${ }^{2}$, DIALLO Alpha Mamadou ${ }^{3}$, Ogountchoro Edwige ${ }^{1}$, DIALLO Mamadou Mansour ${ }^{3}$, Sow Djéneba Sylla ${ }^{4}$, François Djrolo ${ }^{1}$

${ }^{1}$ Service d'Endocrinologie \& Diabétologie du CNHU-HKM, Faculté des Sciences de la Santé, Cotonou (Bénin)

${ }^{2}$ Centre hospitalier universitaire départemental Borgou-Alibori, Parakou, Benin

${ }^{3}$ Service d'Endocrinologie Diabétologie Hopital Donka CHU de Conakry (Guinée)

${ }^{4}$ Faculté de Médecine, Odontostomatologie, Hôpital du Mali, Bamako

*Corresponding author: Gninkoun Comlan Jules, Service d'Endocrinologie \& Diabétologie du CNHU-HKM, Faculté des Sciences de la Santé, Cotonou (Bénin).

Received Date: March 16, 2021; Accepted Date: March 30, 2021; Published Date: April 26, 2021.

Citation: Gninkoun C Jules, A Adébayo, DIALLO A Mamadou, O Edwige, DIALLO M Mansour, et al. (2021) Therapeutic and evolutionary characteristics of Diabetic ketoacidosis after a decade at the University Hospital of Cotonou, Benin. Journal of Endocrinology and Disorders. 5(2): Doi: 10.31579/2640-1045/105

Copyright: (C) 2021 Gninkoun Comlan Jules. This is an open-access article distributed under the terms of the Creative Commons Attribution License, which permits unrestricted use, distribution, and reproduction in any medium, provided the original author and source are credited.

\section{Abstract}

Aim: To evaluate the therapeutic and evolutionary aspects of diabetic ketosis decompensation, a decade after its previous report in our center.

Materials and Method: This was a 3-year retrospective study, including all patients admitted from June 1, 2016 to May 31, 2019 for DKA at the Endocrinology and Metabolic Diseases Department of the National and University Hospital Hubert Koutoukou Maga (CNHU-HKM). Ketosis was defined by the presence of at least 2 acetone crosses on the urine strip.

Results: A total of 196 patients were included. The mean age was 43.73 years \pm 16.2 years with a sex ratio of 0.96 . The prevalence of DKA was $28.99 \%$. The main precipitating factors of DKA were infections $(67.86 \%)$ and non-compliance to the treatment $(29.59 \%)$. The most common infections were urogenital $(23.30 \%)$, respiratory $(18.04 \%)$ and malaria $(32.33 \%)$. The mortality was $2.55 \%$. Male subjects $(84.36 \%)$ had blood glucose levels above $3 \mathrm{~g} / \mathrm{L}$ with a higher mean dose of insulin used (84.71 IU versus $54.29 \mathrm{IU}$ for women $\mathrm{p}=0.008)$. Duration of recovery $(\mathrm{p}=0.008)$ and length of hospitalization $(\mathrm{p}=0.006)$ were statistically longer for men.

Conclusion: The prevalence of ketosis decompensations remains high. The main decompensation factors found were infections and non-compliance to treatment. Improving patient care over the past decade had produced a positive impact on mortality, recovery time and length of hospitalization.

Keywords: diabetes; diabetic ketoacidosis; metabolic complications; infections

\section{Introduction}

Diabetes mellitus is a public health concern worldwide and particularly in low and middle-income countries due to its increasing prevalence while access to care remains challenging [1].

In Benin, between 2001 and 2008, the prevalence increased from 1.1\% [2] to $2.6 \%$ [3]. In 2015, this prevalence was as high as $12.4 \%$ [4]. The course of diabetes mellitus can be marked by acute or chronic complications [5]. Diabetic ketoacidosis (DKA) and hyperosmolar hyperglycemic syndrome (HHS) are the most common acute complications $[1,5]$. The hospital frequency of these acute complications is high in developing countries. In fact, in Ivory Coast and Burkina-Faso the prevalence of DKA was respectively $30.7 \%$ [5] and $59.1 \%$ [1]. The main factors for decompensation were infections, poor adherence to treatment, and lack of awareness toward the disease [1, 5, 6]. In Benin, a study carried out in the endocrinology department of the CNHU-HKM in 2009 reported a prevalence of $21.40 \%$ of diabetic ketosis decompensations (DK). The main triggers found in that study were infections (51.49\%) and non-compliance to treatment $(25.74 \%)$. In addition, the outcome was favorable in $89.1 \%$ and mortality rate was 7.9 $\%$ [7]. 
After a decade, we aimed to evaluate the current prevalence of DK, to identify the main decompensation factors, and to assess the outcome of patients hospitalized for DK at the University hospital CNHU-HKM of Cotonou, Benin.

\section{Materials and methods}

This was a retrospective, descriptive and analytical study involving diabetic patients hospitalized at the endocrinology department of CNHUHKM from June 1, 2016 to May 31, 2019. The hospitalized diabetic patients with a ketonuria at least equal to two crosses [7] with glycemia equal or higher than $250 \mathrm{mg} / \mathrm{dL}$, and positive glycosuria were included in the study.

The following features were collected: age, sex, profession, duration of diabetes, type of diabetes, decompensation factors, body mass index (BMI), blood glucose, glycosuria, ketonuria, kalemia, natremia, parasitic density for malaria, bacteriological analysis of urine, chest x-ray, blood culture, method of insulin administration (continuous versus discontinuous), overall resuscitation duration, length of hospitalization, and outcome (favorable, death).

The ketosis decompensation of diabetes mellitus was defined by a glycemia $\geq 250 \mathrm{mg} / \mathrm{dL}$ and a ketonuria $\geq$ two crosses with positive glycosuria. [7] Regarding the factors causing decompensation, we defined two variables: the infectious causes including pulmonary, urogenital, digestive, skin (other than diabetic foot) infections, diabetic foot and malaria; and the non-infectious causes defined by the noncompliance to treatment, lack of awareness toward diabetes, and intercurrent diseases other than infections (myocardial infarction and stroke).

The other variables were defined as follows:

Patient weight was assessed using de BMI and classified into four (4) categories: Underweight BMI less than $18.5 \mathrm{~kg} / \mathrm{m}^{2}$; Normal: BMI between 18.5 and $24.9 \mathrm{~kg} / \mathrm{m}^{2}$; overweight: BMI between 25 and 29.9 $\mathrm{kg} / \mathrm{m} 2$; Obese: $\mathrm{BMI} \geq 30 \mathrm{~kg} / \mathrm{m}^{2}$ [9].
Method of administration of insulin: Continuous insulin infusion protocol (insulin administered continuously by infusion pump) and multiple insulin injections protocol (administered each hour).

Total recovery time: period from the first insulin injection to the second negative ketonuria.

Length of hospitalization: period from the date of entry to the date of discharge.

Data were collected via an electronic questionnaire designed from the Kobocollect application suite based on the CAPI (Computer Assister Personal Interview) system. The data source was the hospitalized diabetic patient's records and the hospitalization registry.

We checked the consistency of the data and the outliers and duplicates were removed. The analysis was done using the SPSS software version 21 and $\mathrm{R}$ version 3.6.1. We used frequency measurements to describe and analyze the data collected. Thus, the qualitative variable had been described in the form of proportions and quantitative variables in the form of position parameters. The comparisons of the means were made using the $t$ test and those of proportions were made using the $\chi^{2}$ test or the Fisher test as appropriate. Differences were considered statistically significant for p-value less than 0.05 .

\section{Results}

\section{Study population characteristics}

A total of 676 records of hospitalized diabetic patients were examined, among which we identified 196 records of diabetic patients hospitalized for ketosis decompensation. The mean age of the patients was 43.73 years \pm 16.2 years with ranges of 13 and 100 years. There was a female predominance with a sex ratio of 0.96 . The study population consisted of 37 type 1 diabetics (18.87\%) and 157 type 2 diabetics $(80.10 \%)$. Decompensation was inaugural in $39.8 \%$ of patients and, for known diabetic patients, the mean duration of diabetes was 6.09 years \pm 6.62 years with extremes of 0 and 30 years. Excess weight (overweight or obesity) was present in $38.51 \%$ of the subjects included. (Table 1)

\begin{tabular}{|c|c|c|}
\hline & Mean $\mathbf{\pm S D}$ & N (\%) \\
\hline Age (years) & $43.73(16.2)$ & - \\
\hline Gender (Female) & - & $100(51.02)$ \\
\hline Type of diabetes & & \\
\hline Type 1 & - & $37(18.87)$ \\
\hline $\begin{array}{c}\text { Type 2 } \\
\text { decompensation }\end{array}$ & - & $157(80.10)$ \\
\hline Diabetes inaugurated by ketosis & - & $78(39.8)$ \\
\hline Duration of diabetes & $6.09(6.62)$ & - \\
\hline Excessweight & - & $57(38.51)$ \\
\hline Hyperglycemia $\geq \mathbf{3 0 0}$ mg/dL & - & $81(84.37)$ \\
\hline Men & - & $68(68.0)$ \\
\hline Women & - & $141(71.94)$ \\
\hline Ketonuria $\geq+++$ & & \\
\hline
\end{tabular}

Table 1: General characteristics of patients admitted for ketosis decompensation

\section{Prevalence and decompensation factors}

The prevalence of ketosis decompensations was $28.99 \%$ with a $95 \%$ confidence interval of [25. 57-32.41].

Among the decompensation factors, infections were found in $67.86 \%$ (133) of cases, non-compliance with treatment in $29.59 \%$ (58) of cases and in $9.61 \%$ (18) of cases, no factor has not been identified. The infectious sites were dominated by genitourinary site $(23.30 \%)$, respiratory site $(18.04 \%)$ and malaria $(32.33 \%)$. (Table 2). 


\begin{tabular}{|c|c|c|}
\hline Precipitatingfactors & $\mathbf{N}$ & $\mathbf{\%}$ \\
\hline Infection & 133 & 67.86 \\
\hline Non compliancewithtreatment & 58 & 29.59 \\
\hline Intercurrent disease & 6 & 3.06 \\
\hline Ignorance of diabetes & 14 & 7.14 \\
\hline No factor identified & 19 & 9.61 \\
\hline Infectious sites & & \\
\hline Pulmonary & 24 & 18.04 \\
\hline Genitourinary & 31 & 23.30 \\
\hline Digestive & 5 & 3.75 \\
\hline Skin & 20 & 15.03 \\
\hline Diabetic foot & 10 & 7.51 \\
\hline Malaria & 43 & 32.33 \\
\hline
\end{tabular}

Table 2 : Ketosis decompensation factors

\section{Biochemical abnormalities of patients at admission}

The mean blood glucose level was $411 \mathrm{mg} / \mathrm{dL} \pm 1.40$ with extremes of $153 \mathrm{mg} / \mathrm{dL}$ and $900 \mathrm{mg} / \mathrm{dL}$. Among the patients admitted for ketosis decompensations, $71.94 \%$ had ketonuria greater than or equal to 3 crosses.

The electrolytic disturbances were hypokalemia (26.53\%), hyperkalemia (3.06\%) and hyponatremia $(24.49 \%)$.

\section{Therapeutic and evolutionary aspects}

Intensive insulin therapy with an electric syringe pump (continuous) was used in $23.97 \%$ of cases and in $62.75 \%$ of cases it was an hourly (discontinuous) intravenous bolus. The mean duration of resuscitation was 11.16 hours \pm 8.29 with a minimum of 2 hours and a maximum of 53 hours. The average amount of insulin used per patient during resuscitation was $68.84 \mathrm{IU} \pm 60.40$ with a minimum of $10 \mathrm{IU}$ and a maximum of 436 IU. For continuous insulin therapy the mean dose was $63.19 \mathrm{IU} \pm 54.02$ with a minimum of $10 \mathrm{IU}$ and a maximum of $309 \mathrm{IU}$ and for discontinuous insulin therapy the mean was $71.75 \mathrm{IU} \pm 63.59$ with a minimum of $10 \mathrm{IU}$ and a maximum of $436 \mathrm{IU}$.

The outcome of DKA was favorable in $92.85 \%$ of cases. Mortality was $2.55 \%$ and $4.60 \%$ of patients left against advice.

Male sex was the factor found statistically associated with prolonged resuscitation duration $(\mathrm{p}=0.008)$. (Table 3$)$.

\begin{tabular}{|c|c|c|c|}
\hline & \multicolumn{2}{|c|}{$\begin{array}{c}\text { Recovery time } \\
\text { (hours) }\end{array}$} & $\mathrm{p}$ \\
\hline Age (in year) (<40/ $\geq \mathbf{4 0})$ & 12.02 & 10.49 & 0.351 \\
\hline $\begin{array}{c}\text { Gender (Male/Female) } \\
\text { Precipitating factors (Infections/ Other } \\
\text { factors) }\end{array}$ & 13.33 & 9.17 & 0.008 \\
\hline $\begin{array}{c}\text { Method of insulin therapy } \\
\text { (Continuous/Discontinuous) }\end{array}$ & 10.79 & 12.03 & 0.524 \\
\hline Kalemia (low/Normal) & 11.74 & 10.86 & 0.591 \\
\hline Natremia (Low/Normal) & 10.38 & 11.58 & 0.717 \\
\hline Baseline glycemia (mg/dL) (<300/ $\geq \mathbf{3 0 0})$ & 9.28 & 10.74 & 0.705 \\
\hline Baseline ketonuria (++ / $\geq+++)$ & 10.22 & 11.73 & 0.197 \\
\hline
\end{tabular}

Results are expressed as means for all patients

Table 3: Associated factors with the duration of resuscitation in patients admitted for ketosis decompensation

Male sex $(p=0.008)$ and higher baseline glycemia $(p=0.005)$ were statistically associated with a higher mean insulin dose. (Table 4$)$.

\begin{tabular}{|c|c|c|c|}
\hline & \multicolumn{2}{|c|}{$\begin{array}{l}\text { Mean dose of } \\
\text { insulin (IU) }\end{array}$} & $\mathbf{p}$ \\
\hline Age $($ in year) $(<40 / \geq 40)$ & 73.33 & 65.38 & 0.507 \\
\hline Gender (Male/Female) & 84.71 & 54.29 & 0.008 \\
\hline $\begin{array}{c}\text { Precipitating factors (Infections/ } \\
\text { Other factors) }\end{array}$ & 67.41 & 72.24 & 0.741 \\
\hline $\begin{array}{l}\text { Method of insulin therapy } \\
\text { (Continuous/Discontinuous) }\end{array}$ & 63.16 & 71.75 & 0.45 \\
\hline Kalemia (low/Normal) & 66.47 & 74.19 & 0.626 \\
\hline Natremia (Low/Normal) & 82.91 & 67.08 & 0.304 \\
\hline $\begin{array}{c}\text { Baseline glycemia }(\mathrm{mg} / \mathrm{dL})(< \\
\mathbf{3 0 0} / \geq \mathbf{3 0 0})\end{array}$ & 49.63 & 79.24 & 0.005 \\
\hline Baseline ketonuria $(++/ \geq+++)$ & 57.49 & 73.21 & 0.153 \\
\hline
\end{tabular}

Table 4: Associated factors with the mean dose of insulin used in patients admitted for ketosis decompensation 
The mean length of hospitalization was 10.35 days \pm 8.85 with extremes of 1 day and 78 days. Male gender $(p=0.006)$ and baseline glycemia $(p=0.010)$ were statistically associated with mean length of hospitalization. (Table 5).

\begin{tabular}{|c|c|c|c|}
\hline \multirow[b]{2}{*}{ Age (in year) $(<40 / \geq 40)$} & \multicolumn{2}{|c|}{$\begin{array}{c}\begin{array}{c}\text { Lenghof } \\
\text { hospitalization } \\
\text { (days) }\end{array} \\
\end{array}$} & \multirow{2}{*}{$\frac{\mathbf{p}}{0.319}$} \\
\hline & 9.51 & 10.85 & \\
\hline Gender (Male/Female) & 12.16 & 8.61 & 0.006 \\
\hline $\begin{array}{c}\text { Precipitating factors } \\
\text { (Infections/ Other factors) }\end{array}$ & 11 & 8.97 & 0.058 \\
\hline $\begin{array}{l}\text { Method of insulin therapy } \\
\text { (Continuous/Discontinuous) }\end{array}$ & 10.04 & 9.9 & 0.886 \\
\hline Kalemia (low/Normal) & 11.08 & 11.62 & 0.297 \\
\hline Natremia (Low/Normal) & 11.38 & 11.05 & 0.868 \\
\hline $\begin{array}{c}\text { Baseline glycemia }(\mathrm{mg} / \mathrm{dL})(< \\
\mathbf{3 0 0} / \geq \mathbf{3 0 0})\end{array}$ & 8.15 & 11.04 & 0.01 \\
\hline $\begin{array}{c}\text { Baseline ketonuria }(++/ \geq \\
+++)\end{array}$ & 12.53 & 9.5 & 0.095 \\
\hline
\end{tabular}

Results are expressed as means for all patients

Table 5: Associated factors with the lengh of stay in patients admitted for ketosis decompensation

\section{Discussion}

The mean age of the patients was 43.73 years \pm 16.2 years, ranging from 13 to 100 years. This result is similar to the one reported in our previous study [7] in 2009 and to the one reported by Kakoma and al. in 2014 in the Democratic Republic of Congo [6] who found a mean age of 44.8 years with minimum and maximum of 20 and 79 years respectively.

Results are controversial in the literature regarding the sex-ratio [7, 1012]. In our study, a slight predominance of female sex (53\%) was found.

Classically, DKA occurs in patients with type 1 diabetes [13-15]. This is not the case in our work where it was found a predominance of type 2 diabetes. In fact, our study population consisted of 37 type 1 diabetes patients (18.87\%) and 157 type 2 diabetes patients (80.10\%). In addition, ketosis decompensations inaugurated diabetes in $39.8 \%$ of cases. This frequency of inaugural decompensation in black subjects is comparable to that found by other authors such as: Leye and al. [10] in 2013 in Senegal with a frequency of 38.24, Gninkoun and al. [7] in Benin in 2009 with a frequency of $49.5 \%$, and Lokrou and al. [5] in 2014 in Ivory Coast with $49.3 \%$. This predominance of type 2 diabetes found in a context of inaugural decompensations in black individuals could be explained by the existence in black individuals of a form of atypical diabetes occurring in adult patients and whose discovery would be inaugurated by an episode of diabetic ketoacidosis [16, 17]. Indeed, Djrolo and al. [18] in the same center found a prevalence of $5.70 \%$ for this atypical form of diabetes in Cotonou in 2011.

The prevalence of DKA remains high according to the literature. The frequency of $28.99 \%$ found in our work is close to those reported by Bazin and al. [19] in France in 2014 (30.1\%), Lokrou and al. [5] in 2014 in Ivory Coast $(30.7 \%)$. The precipitating factors have not changed over time in our context. Indeed, 10 years ago, Gninkoun and al. reported in the same center that the main precipitating factors of decompensation were infections $(51.49 \%)$, and diabetes treatment interruption (25.74\%)[7].In the current study, these factors are dominated by infections (67.9\%) and (non-compliance to treatment ('29.6\%). These factors seem to be the most reported in other studies as well $[5,7,10,20$, 21].

For DKA treatment, intensive insulin therapy was the main protocol used ( $86.8 \%$ of patients). The mean duration of recovery was 11.16 hours \pm 8.29 and the mean amount of insulin used per patient was $68.84 \pm 60.40$ IU. Lokrou and al. [5] in 2014 in Ivory Coast reported a mean duration of resuscitation of $11.37 \pm 4.5$ hours with a mean amount of insulin of
$52.6 \pm 29.0 \mathrm{IU}$. This difference related to the insulin dose would probably be due to the lower frequency of obesity ( $16 \%$ versus $38.51 \%$ ) in the Lokrou's study, the insulin requirements being function of the patients' weight. A decade earlier, Gninkoun and al. [7] had found in the same center a mean duration of 13.39 hours versus 11.16 hours found in the present work. This improvement observed for the duration of recovery could be explained by a better care of patients due to the implementation of DKA treatment protocol with continuous insulin infusion and telephone call-duty by endocrinologists in 2012 .

We reported a favorable outcome in $92.9 \%$ of cases and death was observed in $2.55 \%$ of patients.Sarr and al. [11] in 2011 and Pouye and al. [22] in 2003 in Senegal had respectively noted a favorable evolution in $91.7 \%$ and $94.1 \%$ of cases respectively. Mortality has declined sharply in recent years and this is confirmed by current data. However, it is worth to notice that high mortality rates are still observed in developing countries. Lokrou and al. [5] in Ivory Coast in 2014 reported a death rate of 5.1\%; Gninkoun and al. [7] in Benin in 2009 found a mortality rate of $7.9 \%$. On the other hand, some authors have reported higher rates of mortality: 17.14\% in South Africa in 2017 [23]; $27.5 \%$ in the Democratic Republic of Congo in 2014 [6]; $40.5 \%$ in Mali in 2007 [24] and 48.7\% in Burkina Faso in 2017 [1]. In the northern countries, the death rates are rather lower: less than $1 \%$ in the USA in 2017 and 2016 [25, 26]; $1.2 \%$ in Spain in 2015 [27]; $1.7 \%$ in China in 2016 [28]. In addition, taking into account the publication dates of the various studies, there is a decrease in mortality rates in the most recent studies and certainly because of therapeutic progress and improvements in technical facilities. In Benin particularly, the lethality of ketosis decompensations has decreased considerably in our de, dropping from $7.9 \%$ in the work of Gninkoun and al. [7] to $2.55 \%$ after a decade confirming the improvement in the care and monitoring of patients in the department. This improvement in patient care has also resulted in a reduction in the length of hospitalization, which decreased from 13.23 days in 2009 to 10.35 days in 2019. While the level of the technical platform, which is higher in developed countries therefore promotes more effective care for patients who otherwise have health insurance; the seriousness of the clinical feature, the delay in admitting patients and the precarious socioeconomic conditions constitute the factors of poor prognosis in the developing countries.

Male individuals seemed to present specificities in our work. Indeed, our results have shown that $84.36 \%$ of male subjects had a glycemia above $300 \mathrm{mg} / \mathrm{dL}$. Even if it is not obvious to explain this result, the fact that the 
mean insulin dose was higher in men (84.71I IU versus 54.29 IU in women $\mathrm{p}=0.008$ ) is quite understandable. The hourly doses of insulin are determined by the glycemia during resuscitation and the men had the highest blood sugar levels. In addition, the much longer duration of resuscitation found in our study in men $(\mathrm{p}=0.008)$ constitutes an additional argument.

\section{Conclusion}

Our study showed that the prevalence of DK is still high and that the main decompensation factors have not changed significantly over time. Improving patient care over the past decade had produced a positive impact on mortality rate, which has been reduced by a factor of three, with a marked decrease in the duration of resuscitation and length of hospitalization.

\section{References}

1. Bonkoungou P, Lankoandé M, Guira O, Saloukou KE, kaboré RA, Zinsou A et al. (2017) Complications aiguës métaboliques du diabète sucré dans le Service de Réanimation Polyvalente du Centre Hospitalier Universitaire Yalgado Ouédraogo de Ouagadougou au Burkina Faso. Revue Africaine et Malgache de Recherche Scientifique/Sciences de la Santé.;5(1): 36-41.

2. Wild S, Roglic G, Green A, Sicree R, King H. (2004) Global prevalence of diabetes: estimates for the year 2000 and projections for 2030. Diabetes care. 27(5):1047-1053.

3. Gning SB, Thiam M, Fall F, Ba-Fall K, Mbaye PS, Fourcade L. (2007) Le diabetesucre en Afriquesubsaharienne. Aspects epidemiologiques, difficultes de prise en charge. Médecinetropicale.67(6):607-611.

4. Djrolo F, Adoukonou T, Houehanou C, Houinato JD, Houinato D. (2015) Diabetes in Borgou Department in Benin: Prevalence and associated factors. Journal of DiabetesMellitus.5(02):9096.

5. Lokrou A, Kouassi F. (2014) Bilan de 9 années de prise en charge de l'acidocétose du diabétique africain adulte en Côted'Ivoire. Médecine des maladies métaboliques.8(3):330-334.

6. Kakoma PK, Kadiebwe DM, Kayembe AM, Makonga PK, Bugeme M, Mukuku O. (2014) Acidocétose diabétique chez l'adulte à l'Hôpital Sendwe de Lubumbashi: à propos de 51 cas. Pan African Medical Journal.17(1):1-5.

7. Gninkoun CJ, Alassani AS, Sagna Y, Adjagba P, Djrolo F. (2016) Diabetic Ketosis Decompensations at the National Hospital in Benin (West Africa), What Did We Learn about the Precipitating Factors? Journal of Diabetes Mellitus. 6(04):301306.

8. Ogden CL, Carroll MD, Curtin LR, McDowell MA, Tabak CJ, Flegal KM. (2006) Prevalence of overweight and obesity in the United States, 1999-2004.295(13):1549-1555.

9. Acakpo A, Fayomi B, Djrolo F, Kolanowski J, Agueh V, Makoutode M, Sahaha J-B. (2000) Prévalence et étude des facteurs déterminants de l'obésite à Cotonou. Louvain médical.;119(7):276-281.

10. Leye MY, Leye A, Ndiaye N, Ngo VB, Touré PS, Ndour M, Fall B. (2016) Aspects épidémiologiques et diagnostiques de la cétoacidose diabétique en milieu hospitalier à Dakar. Analyse de 102 cas au CHU de Pikine. Revue Africaine de Médecine Interne.3(2):8-11.

11. Sarr A, Diedhiou D, Ndour-Mbaye N.M, Leye Y.M, Ka-Cisse M.S, Leye A, et al. (2011) Ketoacidosis in type 1 diabetesmellitus: 73 cases in Dakar. Le Mali medical.26(4):5054.

12. Guira O, Tiéno H, Bagbila A, Sagna Y, Nikiéma P, Yanogo D, et al. (2013) Typologie des cétoses diabétiques et facteurs associés aux dysnatrémies à la phase initiale de leur prise en charge à Ouagadougou (Burkina Faso). Médecine des Maladies Métaboliques.7(6):539-542.

13. Kitabchi AE, Umpierrez GE, Murphy MB. (2015) Diabeticketoacidosis and hyperosmolar state. International Textbook of Diabetes Mellitus.799-814.

14. Dave J, Chatterjee S, Davies M, Higgins K, Morjaria H, McNally P, et al. (2004) Evaluation of admissions and management of diabetic ketoacidosis in a large teaching hospital. Practical Diabetes International.21 (4):149-153.

15. Wang ZH, Kihl-Selstam E, Eriksson JW. (2008) Ketoacidosis occurs in both Type 1 and Type 2 diabetes - a populationbased study from Northern Sweden. Diabetic medicine. 25(7):867-870.

16. Desai D, Mehta D, Mathias,P, Menon G, Schubart UK. (2018) Health care utilization and burden of diabetic ketoacidosis in the US over the past decade: a nationwide analysis. Diabetes Care. 41(8):1631-1638

17. Smiley D, Chandra P, Umpierrez GE. D. (2011) Update on diagnosis, pathogenesis and management of ketosis-prone Type 2 diabetes mellitus. Diabetes management.1 (6):589.

18. Djrolo F, Amoussou-Guenou KD, Wanvoegbe A, Glitho S. (2011) Le diabete sucré atypique à tendance cétosique à Cotonou. Louvain Med.130(4):97-98.

19. Bazin A, Meillet L, Schillo F, Desmettre T, Borot S. (2016) Admissions aux urgences pour hypoglycémie ou décompensation hyperglycémique chez les patients diabétiques: un passage obligé? Médecine des Maladies Métaboliques. 10(3):275-279.

20. Suwarto S, Sutrisna B, Waspadji S, Pohan H.T. (2014) Predictors of five days mortality in diabetic ketoacidosis patients: a prospective cohort study. ActaMedicaIndonesiana. 46(1): 18-23.

21. Alourfi Z, Homsi H. (2015) Precipitating factors, outcomes, and recurrence of diabetic ketoacidosis at a university hospital in Damascus. Avicenna Journal of Medicine. 5(1): 11-15.

22. Pouye A, Leye A, Ndongo S, Ka MM, Dia D, Fall S, et al. (2003) Acidocétose diabétique dans un service de Médicine interne. Dakar médical. 48:108-111.

23. Ndebele NFM, Naidoo M. (2018) The management of diabetic ketoacidosis at a rural regional hospital in KwaZulu-Natal. Afr J Prim Health Care Fam Med. 10(1): 1612.

24. DiarraSimaga MT. (2007) Complication's métaboliques aigues du diabète dans le service de réanimation de l'hôpital Gabriel Toure: Aspects épidémiocliniques. [Thèse de médecine]. Bamako 2007: Université de Bamako, Faculté de Médecine de Pharmacie et d'Odontostomatologie,

25. Cardoso L, Vicente N, Rodrigues D, Gomes L, Carrilho F. (2017) Controversies in the management of hyperglycemic emergencies in adults with diabetes. MetabClin Exp. 68:4354.

26. Anzola I, Gomez PC, Umpierrez GE. (2016) Management of diabetic ketoacidosis and hyperglycemic hyperosmolar state in adults. Expert review of endocrinology \& metabolism. 11(2):177-185.

27. Guisado-Vasco P, Cano-Megías M, Carrasco-de la Fuente M, Corres-González J, Matei AM, González-Albarrán O. (2015) Clinical features, mortality, hospital admission, and length of stay of a cohort of adult patients with diabetic ketoacidosis attending the emergency room of a tertiary hospital in Spain. Endocrinología y Nutrición (English Edition). 62(6):277-284.

28. Xu Y, Bai J, Wang G, Zhong S, Su X, Huang Z, et al. (2016) Clinical profile of diabetic ketoacidosis in tertiary hospitals in China: a multicentre, clinic-based study. Diabetic Medicine. 33(2):261-268. 